\title{
Learning to play in digital games
}

There is growing interest in the use of games for educational purposes, particularly with regard to teaching curriculum subjects. Much of the research however has focused either on the content of games or the learning theory they illustrate. This paper presents a methodology that allows for an examination of how players learn to play. An understanding of this process is arguably crucial for incorporating games into educational systems. Three case studies are presented that illustrate the application of this method. We also evaluate its usefulness and limitations. The paper concludes with a discussion of issues in researching learning from games, and suggestions for how research methods in this area might be developed. 


\section{Biographical information}

Caroline Pelletier is a researcher at the London Knowledge Lab, Institute of Education.

c.pelletier@ioe.ac.uk

Martin Oliver is a senior lecturer at the London Knowledge Lab, Institute of Education, and is an editor of $A L T-J$, the journal of research in learning technology.

m.oliver@ioe.ac.uk 


\section{Learning to play in digital games}

\section{Introduction}

In this paper, we explore the issues involved in studying learning in the context of playing digital games. Existing accounts of learning and digital game-based play are examined. We discuss a methodology for studying the process of learning to play in these contexts. Understanding this is, arguably, a pre-requisite for incorporating games into educational systems, since it throws light on how games function as texts and therefore how they might be used for teaching and learning. The method is applied to three case studies, and its value and limitations are then discussed. The paper concludes with the identification of issues in researching learning from games and suggestions for further research in this area.

\section{Background}

There is growing interest in the usage of digital games for educational purposes (e.g. Egenfeldt-Nielsen, 2004; Dawes \& Dumbleton, 2001; Gander, 2000). Two areas of research focus in particular on the relationship between the design of the game and the experience of the player during play, examining how and what players learn through play and how games function pedagogically, or how they teach players how to play.

The first of these areas adapts standard software evaluation procedures to identify the informational content of games - what they might be said to cover in terms of subject matter. In the UK, the BeCTA (British Educational Communications and Technology Agency) and TEEM (Teachers Evaluating Education Media) reports into the educational benefits of computer games are the most prominent examples of this, examining the cognitive and social processes involved in playing a number of games (Dawes \& Dumbleton, 2001; McFarlane et al, 2002). This kind of research defines the educational potential of games in terms of the opportunities for players to evaluate information, hypothesise solutions and work in groups. However, how such opportunities are taken up is rarely researched. The TEEM report, for example, reviewed the informational content of a number of digital games and collected feedback though post-play focus groups and questionnaires. But it did not observe the process of playing, or research the nature and quality of moment-by-moment social and technological interactions and how these might relate to each other. As a result, although BeCTA and TEEM concluded that learning was taking place, their method of analysis could not account for it. The reports suggested that skills such as strategic thinking and problem solving could be developed through game play, but were not in a position to explain how students develop specific skills, what might count as evidence for such skills within the context of playing a game and whether there was transference to other contexts. This is largely because there is no established theory or method for analysing the process of game play in terms of learning.

The second of these areas focuses on the learning principles which computer games demonstrate. In his book, What games have to teach us about learning and literacy, James Gee (2003) outlines the theory of learning embedded in computer games. He argues that when people learn to play video games, they are learning a new social literacy, which involves not only decoding the game as text but also knowing various ways of acting, interacting, valuing and feeling. Learning in games is defined not so 
much as an outcome as part of the process of playing, and relates less to the content of the game than to the complexity of its design; according to Gee, learning and playing are simultaneous and largely synonymous processes. The pleasures and frustrations of playing are akin to those of learning.

Gee argues that it is only 'good' games that involve complex learning processes these are distinguished from 'bad' games that presumably don't. However, as with BeCTA's and Teem's research, Gee does not include a method for researching learning and playing in different contexts, and therefore for identifying what might count as a 'good' game. Without this, researching how learning relates to the nature of the game and the social and cultural dimension of playing remains problematic. Gee makes a strong argument for learning through game play, but his approach does not give researchers the tools to investigate how different games and contexts influence learning.

Although the two approaches detailed here are very different, therefore, they share a common problem. What is missing from both, and from the literature on learning and digital games in general, is a method that looks at the process and outcomes of play, explaining how this relates to the design of the game text as well as the social and cultural aspect of play. This gap in the research was pointed out by Squire in 2002, who argued in favour of naturalistic studies of game-playing experiences and the kind of practices people engage in while gaming:

What's missing from contemporary debate on gaming and culture is any naturalistic study of what game-playing experiences are like, how gaming fits into people's lives, and the kinds of practices that people are engaged in while gaming. Few, if any researchers have studied how and why people play games, and what gaming environments are like. [...] Investigators might benefit by acknowledging the cultural contexts of gaming, and studying game-playing as a cultural practice. If nothing else, it highlights the importance of putting aside preconceptions and examining gamers on their own terms. (ibid: $2-3$ )

His critique of research into learning from games is stronger still: "we know very little about what [people] are learning playing these games (if anything)" (p4). It is this particular challenge that will be addressed within this paper. In the next section, a research methodology is presented that can contribute to this aim.

\section{A new methodology for researching learning and games}

Squire's review of computer game research suggests several theoretical frameworks that could provide a social, cultural insight into learning and game playing (2002). One of these is Activity Theory. In this section, this framework will be outlined and then operationalised as a research methodology.

As Squire describes, Activity Theory emerged from Vygotsky's psychological research into learning (and specifically from his discussion of the mediating role of artefacts in cognition). The initial formulation of Activity Theory involved the proposal that intentional human action is invariably mediated by a tool, although it is noted that the tool may be conceptual or symbolic (such as an idea or language) rather than necessarily being embodied (such as a hammer or computer). Within this system, 
the person acting is referred to as the Subject, their intention (or objective) is referred to as the Object and the mediating artefact is referred to as a Tool.

This initial analytical framework was subsequently expanded to take the cultural and historical context of activities into account explicitly (Kuutti, 1996; Engeström, 2001; Squire, 2002). This extended the representation to cover the community within which the activity takes place, the rules that hold within that community and the way in which work is organised in order to achieve an objective (its division of labour). As with the first iteration of the system, some relationships between elements of the system are implied - so, for example, the Community is related to the Subject only through Rules, and likewise is related to the Object only through its Division of Labour (Figure 1). Following the conventions of Kuutti (1996), the proposition that human activity is always mediated by tool use is represented by the dashed arrow; this relationship is implied by the two other relationships (between Subject and Tool and between Tool and Object), rather than being a direct relationship.

$<$ Figure 1 here $>$

Within this perspective, 'contradictions' (breakdowns, disagreements, etc., in the activity system) are described as an important motivation for learning (Engeström, 2001). This implies that learning is an active, creative process motivated by problems, rather than something that follows from the smooth operation of successful activity systems. Because of the importance of these problematic or 'contradictory' moments for learning, their identification and analysis will form the basis of the approach developed here. This is not to suggest that learning is reducible to problem solving. In this research, we focus on contradictions because of the nature of our research question and the object of our research - game play. In other research contexts, this understanding of learning is unlikely to suffice. This is not to highlight a problem with the definition, but rather make clear that our interest is in understanding the nature of specific, selected processes, rather than put forward a theory of learning as a general phenomenon. Here, we examine how individuals learn to progress in a game, and it is this aspect of game play that is the focus of our analysis. 'Learning' in games could be accounted for from other perspectives, such as learning about visual design, narrative structure, social relations in game culture and so on. However, we seek to make some general comments about learning to play by looking specifically at tool use and the nature of the pedagogic design that teaches players how to use the game as a tool. The extent to which this is reducible to problem solving will be considered in the discussion that follows.

\section{Accounting for learning}

As discussed above, the basic unit of analysis within Activity Theory is not the individual subject, nor a tool, but a system that considers intentional tool use within a cultural context. This implies that learning is a property of the system, rather than the learner.

However, subjects have agency in a way that tools, rules, etc., and arguably even communities (conceived of in the abstract) do not (Nardi, 1996), making it plausible that this is a property that should be attributed to subjects in preference to other components of the system. Moreover, in the context of learning from games, there may well be some situations in which it seems improbable that the other parts of the 
system could be 'expanded' (in Engeström's sense). For example, in a system that represents a child playing a game on a console, attempting to complete a task devised by a community of game designers, there is little possibility of feedback to enable the designers to change the rules, object, tool, etc. Consequently, the only opportunity for 'expansion' when contradictions arise will involve the subject learning how to use the tool better or developing a better understanding of the rules devised by the developers. Roussou (2003) has used this analysis to provide an account of children's learning from Virtual Reality exhibits designed for use in museums. This work suggested that resolved contradictions between the subject and tool indicate examples of skill development (understood as proficient use of a tool) and that resolved contradictions between the subject and rules illustrate examples of enculturation.

Another important consideration in this respect concerns the status of claims made about learning. Systems within Activity Theory are representations of activities; as such, these are accounts of practice. Such accounts are not general but specific to the subject of analysis (in this case, learning the strategies which enable progression). Alternative representations could be produced, depending on one's interest in the phenomenon under analysis. Similarly, if we consider Wenger's related discussion of communities of practice (1998), we must recognise that people are simultaneously members of multiple communities. Which community is represented in a particular system depends on the purpose of the analysis. Thus strictly, what can be produced from these analyses are accounts of learning; they are subjective interpretations of observations, and their credibility will have to be judged on the quality of the data gathered and analysis. This might be demonstrated in a number of ways, such as presentation of data alongside an example of its analysis (a transcript, or a video excerpt in an online article), reports on inter-rated reliability (perhaps focusing on analysing examples of disagreements) or triangulation with other research methods (such as interviews exploring the player's own interpretations, perhaps prompted by re-playing a video of particular contradictions).

\section{Levels of system}

Further refinement of Activity Theory has led to the development of three levels of analysis (Kuutti, 1996):

- Activities (high-level plans such building a house).

- Actions that contribute to the activity (such as building a wall).

- Operations that contribute to each action (such as laying a brick), which are routine or automatic unless something goes wrong (a contradiction arises).

This hierarchy thus supports analysis at the strategic level of game objective (complete a level, beat a 'boss'), the tactical level (gather the remaining tokens, follow a particular pattern of movements) or the operational level (move the avatar forward, press a particular button). Importantly, it also permits these to be integrated. The implication of this is that a taxonomy of learning can be created that ranges from near-trivial button presses to strategic knowledge. 


\section{Operationalising the theory for analysis}

The discussion above lays the groundwork for the development of a research method and instrument. The method involves close analysis of video recordings of play, using a table to record the players' actions. While some level of description may be useful for the entire recorded session, particular attention (and corresponding detail) is given to contradictions (failures, mistakes, etc.). Evidence is then sought to see whether these contradictions are resolved - for example, by re-trying the problem with a different strategy and succeeding.

The table below illustrates how we operationalised this theory as a research method.

\section{$<$ Table 1 here $>$}

Three case studies are presented that use this approach to research learning to play. The first involves the analysis of a popular commercial title (Harry Potter and the Chamber of Secrets), chosen for its simplicity (it is aimed at younger players). Having used this case to demonstrate the potential of the approach and explain how it was refined, studies two and three apply it to a more sophisticated game (Deus Ex), identified by Gee as a prime example of a 'good' game (and thus one that ought to demonstrate 'good' pedagogic design). These case studies are not samples from which to make generalisations about learning in games, but demonstrations of a method of analysis by which learning in games can be investigated empirically.

\section{Case Study 1: Harry Potter}

The study is based on video observation of a teenager playing the game Harry Potter and the Chamber of Secrets. She was filmed for 25 minutes, as part of a lunchtime game playing club at her school. This teenager was chosen for the study as she had played the same game consistently over several weeks and was highly motivated to progress through it. For this case, she attempted to complete a level she had not played before.

The table of analysis (see Table 1) provided a mechanism for documenting learning, but further inference was required to fully analyse it. By working at the level of operations, most instances of learning that were seen were low-level, such as learning about properties of one object. We concluded that another step was needed. Reviewing the individual learning tactics (e.g. "click on an object") recorded in the table, a series of learning strategies were then proposed, equating to learning-oriented Actions in Activity Theory. This involved trying to provide reasons that could explain the observed instances of learning. For each, a rule was proposed and then the table reviewed so that it could be refined by testing its explanatory power with each appropriate observational instance. This process was repeated until a set of rules was developed that explained all of the observed behaviour. This, we propose, constitutes the set of rules (in the Activity Theoretic sense) followed by the player. Note that these rules are a proposed explanation; they were not made explicit - and may not even be recognised - by the player or the games designer. They also exclude improvements in skill, since this category relates to contradictions between subject and tool, not subject and rules. The rules were:

1. Spot unusual objects and click on them. 
2. If you can't progress (e.g. a door won't open), systematically explore the area until you find something you missed. (Note: this typically led to uses of rule 1.)

3. If you see a block, levitate it onto something.

4. If you've run out of things to click on, move on to a new area.

5. If you haven't explored an area, do so.

6. If there is a threat, move past it carefully (positioning and timing).

Rule 1 deals with learning about the properties of objects. Rules 2 and 3 relate to learning game conventions. Rules 4-6 relate to learning about in-game spaces. Between them, these six rules motivate and justify every operation observed during the session.

Analysing the strategies for action in this way suggests that this is a relatively simple game. The majority were of the same type - clicking on objects to determine their properties. However, this is not necessarily a criticism - the player clearly enjoyed the game, and continued playing it for several weeks following our research. Indeed, such simplicity may be appropriate for a game intended to engage people who are not experienced gamers. However, it does illustrate that the process of learning to play this game is relatively brief and limited in scope.

\section{Case study 2: Deus Ex with the training level}

This study involved an adult game player who was familiar with a range of titles but had not played this game. She played the game for around two hours over two sessions, starting with the training level and then undertaking the first mission. Two cameras were positioned to film the screen and her use of the computer.

Unlike the previous game, the training level here serves to provide a structured curriculum for new players. Twenty five separate activities were introduced and applied; for example, learning how to access goals, how to use items (including weapons), how to move in particular ways (stealthily, how to jump), as well as conventions such as information being stored in data cubes. In addition, eight separate tasks were learned that were not specified by the instructions within the game (e.g. that the avatar cannot die in the training level and guards can hear you).

The strategies guiding play within the training level were:

1. When moving into a new area, look around to take note of potentially salient features

2. If you're under fire, head for cover

3. When you see cover, crouch and move towards it

4. If one route is repeatedly unsuccessful, try another 
5. (If sneaking doesn't work, try running past) - attempted in the stealth section, but abandoned as not generally successful

6. If you can't destroy the threat with the resources at hand, there must be some other resources hidden in the area you haven't yet found

7. If you see an unfamiliar object, right-click it (e.g. books) to see what you can do with it

8. If unable to manipulate an object, browse the menus (e.g. nanokeyring)

9. If you reach an impasse, move through all the information screens (inventory, goals, conversation list, etc.) to see if any information or tool has been neglected

10. If you can't cross a space (meet a challenge?) then try successful approaches from other kinds of game to see if the same strategy transfers to here.

These evolved to form a more sophisticated set of strategies by the end of an hour's play of the opening mission:

1. Move through the space until something happens

2. Stay behind cover until you shoot

3. If in combat, fall back to find cover

4. If progress fails, explore earlier areas to find more resources

5. If you see an enemy, hide until they've passed

6. If you see a body, search it

7. After a noisy combat, check and see if anyone else is coming

8. If no one around, then run

9. If challenge too difficult, try another route

10. If stealth approach fails, try shooting from cover

11. If guards running away, shoot them (later this changed to letting guards run away)

12. When you've got past something difficult, save the game

The fact that twice as many strategies are necessary to explain the player's actions, compared to the first case study, highlights the relative complexity of each game. This analysis also raised a number of research issues. Firstly, there was evidence of the player forgetting how to perform certain tasks and overlooking objects that have in previous experience been shown to be significant. There are two possible ways this could be interpreted; it could be a recall problem; or it could be an inability to transfer 
a successful strategy to a new (albeit similar) context. It is however useful that this methodology recognises forgetting as this is often neglected in studies of game play. Secondly, there was evidence of transfer from other contexts. However, we were not in a position to decide which context they were transferred from, whether this was from another game or from experiences earlier within Deus Ex. For example, the attempt to cross a water barrier by jumping across floating crates was reminiscent of actions characteristic of the platform genre, but there is no way of being certain that this was the case. Thirdly, the method has also demonstrated the processes of developing strategies of play. For example, on the first mission, the player tried alternative ways of reaching a location, first sniping, then running and finally moving stealthily past guards.

These issues raise some question about the design of the structured curriculum in the training level. If forgetting does occur, it suggests there might be alternative, more effective ways for game designers to teach players the rules of their game. This clearly assumes that such is the designer's intention. If the designer has no such intention, however, there would seem to be little value in a training level.

\section{Case study 3: Deus Ex without the training level}

This case study involved an adult player who had relatively limited experience of game playing. He played the first mission of Deus Ex for approximately two hours (of which the first hour has been analysed for this paper), but unlike the player in case study two, did not work through the training level beforehand. This was initially an oversight, but provides a point of contrast with the previous case study. However, the player in this case study was also far less experienced than the one in case study two. This allows us to examine differences in strategies for action employed in the same game by different players.

This player's strategies were as follows:

1. If unsure about how to design the character, allocate points and see what happens.

2. If unsure how to proceed, check the inventory screen.

3. When in a new area, glance around to see what's there.

4. When shot, look around to see where the avatar has been shot from.

5. When in combat, stand still and shoot the enemy.

6. When enemy is in sight, try moving towards them behind cover.

7. If a weapon stops working in combat, change weapon.

8. If all other options fail in combat, try direct assault.

9. If the health screen indicates injury, heal the avatar.

10. If resources are low, try moving past enemies without being seen. 
11. If progress seems too difficult, go back and look for things you may have missed.

12. If unsure how to interact with an object, click on it.

This case study is useful as a contrast to the previous one, in that it highlights takenfor-granted elements of play that proved problematic here. For example:

- It took 35 minutes before the player realised their avatar could pick things up.

- The meaning of conventions (such as converging crosshairs) was not apparent; the player seemed to think these would result in shooting the target, rather than improved aiming.

- The player never learned how to crouch, which is vital to a stealthy strategy.

The value of this case study is that it allows us to examine issues of transfer. Several examples were noted:

- The player knew how to draw a gun and make other items active (helpful transfer)

- The player attempted to talk to other characters, indicating that he knew they had further information to provide. However, he did not know how to activate them in this game (problematic transfer)

- The player tried to pick up ammo by walking over crates (a convention of many 'first-person shooter' games), rather than breaking them open (problematic transfer).

- When facing a threatening character, the player's usual strategy was to confront them head on; over time, he learned that a covert approach was usually more likely to be successful (unhelpful transfer).

- Having knocked enemies unconscious, the player then tried to kill them; he later realised that it is only necessary to incapacitate them or scare them away (unhelpful transfer).

The player in this case study tried as many strategies as the player in case study 2 , but was less successful; so although several strategies were developed, none met the game's requirements. So whereas the player in case study 2 can build on her existing and successful strategies, the player in case study 3 will still need to develop successful ones. It is not unreasonable to argue that the case study 2 player has learned from the training level to develop robust strategies, whereas the player in case study 3 is unable to do this. Having not completed the training level, he draws on his previous experience of games - but this is not always helpful. This suggests that successful strategies are developed by discriminating between knowledge that is appropriate in a new context and that which is not. Transfer happens, but not always appropriately. 


\section{Discussion}

The methodology developed here enabled an analysis of the process whereby players learn to play and progress in a game. It enables a systematic documentation of game play; it provides a way of analysing this to identify how learning takes place; this then forms the basis for the development of rule sets that can be used to explain the player's actions and which summarise what has been learnt at a strategic level. As shown in case study 2, we can also identify how strategies evolve over time in response to new challenges within the game.

Two implications of this approach are worth highlighting. Firstly, it provides a basis for comparing games in terms of the kinds of strategies that they are likely to demand from the player. Secondly, it enables the analysis of how learning such strategies takes place in different contexts and with different players; learning is not understood to flow unproblematically from the game as a text to the player, but to emerge from the interaction between various elements in the socio-cultural system. Our case studies have defined the contours of this system narrowly, by examining the interactions between one player and one game, but this does not invalidate the method as a way of investigating learning through play. The activity system could be expanded to take a broader perspective on the context of play. This would need to happen to explore how applicable the method was to other contexts and also research questions.

Having said this, our approach does raise a number of issues. The first is that the process we followed reveals learning in action. Its focus on resolving contradictions, rather than on listing successful behaviours, means that it is essentially dynamic; it is about learning as a process. Claims can be made with confidence, since evidence of learning is identified, but the method reveals only a sub-set of what the player knows; it will not for example necessarily reveal what they knew before the observed session. This means that the method may yield more data in observing relative novices rather than skilful players. It also highlights that biographical data on player' previous experience is required to inform judgements about what is bring observed, why contradictions may be occurring and how strategies evolve.

This need for biographical information is also closely related to the second issue: that of transfer, which Squire (2002: 8-9) identifies as important to understanding the educational value of games.

Unfortunately for educators looking to use games to support learning, this sceptical transfer limits what we hope players might learn from gaming. While pundits and theorists suggest that game-playing might be increasing kids critical thinking or problem-solving skills [...], research on transfer gives very little reason to believe that players are developing skills that are useful in anything but very similar contexts. A skilled Half-Life player might develop skills that are useful in playing Unreal Tournament $[\ldots]$ but this does not mean that players necessarily develop generalizable "strategic thinking" or "planning" skills.

The case studies suggest that players $d o$ transfer rule sets both from other games and across one section of the game to another. We have been able to deduce where transfer is happening, but not where the tactics that are employed are transferred from - these might be from previous game play, from earlier in the same game, from watching others' play, and so on. 
In addition, we have shown that transfer is not always appropriate. In some cases it did allow problems to be solved. In others, however, trying to use tactics learnt in other settings caused more problems than it solved. Additionally, some of the rules mentioned in these games are unlikely to transfer (such as responding to the presence of blocks by trying to levitate them). We also showed examples of forgetting something which we argue is closely related to the problem of transfer, in that it can be explained by the failure to apply tactics learnt in one part of the game to another.

A third concern is the interpretation and classification of observed behaviours, and in particular the assertion that a particular action did or did not work. Such claims are difficult to justify without assuming (rather than knowing) the intentions of the player. For example, when the player clicks repeatedly on different kinds of objects, two interpretations are possible. The first is that the player is trying to make the object respond but it does not - which might be classed as a failed operation. The second is that the player is seeking to understand whether such objects are worth clicking - in which case the lack of a response is useful data; they may learn from this that objects of a certain kind are unresponsive and not bother to click on more of them in the future. There may also be cases in which the player makes a lucky guess improvements or decreases in performance cannot therefore always be easily attributed to sustainable changes in levels of skill. In some cases, distinction between such options is possible on the basis of future in-game action (such as ignoring more examples of the same object), but nevertheless this does highlight the complexity of interpretation.

The fourth is that some operations are hard to gather evidence about. Unless tools for eye motion tracking are introduced, for example, it is hard to observe when the player is 'reading' the interface in order to spot a distinctive section of wall or assess the avatar's health. As well as being difficult to notice, such operations may prove hard to record in the table, since they may be ongoing rather than discrete events. ("View the screen", for example, is an essential and almost ubiquitous operation - although there were examples of the player looking away - but these were not recorded alongside discrete actions such as button presses.)

The fifth concerns the focus upon problem solving. Whilst this did prove powerful as a focus, allowing strategies of play to be identified and analysed, some changes in behaviour were not motivated by problems per se. When examining the player's level of skill in tool use, this was manifested in the lack of obvious transition between 'unskilled' and 'skilled' performance. Rather than being binary states, there is a continuum of skilful performance (although in some in-game situations there is a binary distinction between "good enough" and inadequate). Playing more skilfully could be expressed as a contradiction between subject and rules of 'good' (as opposed to 'adequate') play, but the use of contradictions to explain this seems forced.

Finally, it would be possible to provide a finer-grained reading of the action than was undertaken if each key press or mouse movement could be recorded. This would prove impractical for long sections of video, but could prove useful for detailed analysis of key incidents.

\section{Conclusions}


Previous research on games and learning have tended to focus not on learning per se but on issues of curriculum integration based on inferences about the game itself (its content), rather than from instances of play. Where the process of play has been commented upon, this has drawn on the player's own perception and self-report, rather than on observational analysis. The methodology outlined in this paper therefore provides a new perspective that focuses on the particular, rather than making general claims about a game's pedagogic design or its players. This has enabled us to talk about learning as problem solving, as the development of strategies and as the improvement of skill in a more precise way than was previously possible. This is relevant to two audiences. Firstly, educators interested in the potential of games for school-based learning. Secondly, game designers investigating the relationship between game design and player motivation.

This method may be useful in substantiating current discussions about games and learning by providing evidence that can be used to support or counter particular claims. It may also have value in informing the design of educational software. Although there is substantial interest in using games to teach curriculum content, there are few examples of this being done successfully, precisely because it remains unclear how to evaluate the process of learning in games. This method enables an investigation of some of the ways in which learners learn to play, and thus how educational software might draw on principles of game design. For game designers, it can be used to highlight what motivates players to solve problems and persist in playing in spite of failure - this may not in fact always relate closely to the quality of the problems to be solved but to other factors such as the nature of the representation, the quality of the graphics and audio, or other aspects of a game. This highlights that although this approach can identify how learning to play takes place with some confidence, it does not place a value on this. How to value the learning that is taking place will depend on which value framework is being implemented. Within education, this will relate to the curriculum and particularly assessment. For game designers, it will relate to the game's intended audience and what might be an appropriate level of complexity given the player's likely experience and interest in playing a particular title.

\section{References}

Dawes, L. \& Dumbleton, T. (2001) Computer games in education project. http://www.becta.org.uk/page documents/research/cge/report.pdf; URL last accessed $15^{\text {th }}$ July, 2004.

Egenfeldt-Nielsen, S. (2004) Practical barriers in using educational computer games, work in progress. http://www.it-c.dk/people/sen/papers/Practical\%20barriers\%20in $\% 20$ using $\% 20$ educational $\% 20$ computer $\% 20$ games 0.6 .doc; URL last accessed $15^{\text {th }}$ July 2004.

Engeström, Y. (2001) Expansive learning at work: towards an activity theoretical reconceptualization, Journal of Education and Work, 14 (1), 133-156.

Gander, S. (2000) Does learning occur through gaming? Electronic Journal of Instructional Science and Technology (E-JIST), 3 (2), 28-43. 
Gee, J. (2003) What video games have to teach us about learning and literacy (New York, Palgrave MacMillan).

Kuutti, K. (1996) Activity theory as a potential framework for human computer interaction research, in: B. A. Nardi (Ed.) Context and consciousness: Activity theory and human-computer interaction (Cambridge MA, The MIT Press), 17-44.

McFarlane, A., Sparrowhawk, A. \& Heald, Y. (2002) Report on the educational use of games: An exploration by TEEM on the contribution which games can make to the educational process (Cambridge, TEEM).

Nardi, B. A. (1996). Studying context: A comparison of activity theory, situated action models, and distributed cognition, in: B. A. Nardi (Ed.) Context and consciousness: Activity theory and human-computer interaction (Cambridge MA, The MIT Press), 69-102.

Prensky, M. (2001) Digital game-based learning (London, McGraw-Hill Education)

Roussou, M. (2003) Interactivity and Learning: Examining young learners' activity within interactive virtual environments (Unpublished $\mathrm{PhD}$ report, University College London).

Squire, K. (2002) Cultural framing of computer/video games, GameStudies, 2 (1), http://www.gamestudies.org/0102/squire/. URL last accessed 20 $0^{\text {th }}$ July, 2004.

Wenger, E. (1998) Communities of Practice (Cambridge, Cambridge University Press). 
Community

Rules

Division of Labour

Tool

Subject

Object

Figure 1: An Activity System 


\begin{tabular}{|c|c|c|c|c|c|c|c|}
\hline $\begin{array}{l}\text { Time } \\
\text { index }\end{array}$ & Activity & Action & Operation & $\begin{array}{r}\text { Contra } \\
\text { betw }\end{array}$ & $\begin{array}{l}\text { iction } \\
\text { n... }\end{array}$ & Rationale & $\begin{array}{l}\text { Evidence of } \\
\text { learning }\end{array}$ \\
\hline \multirow[t]{2}{*}{$07: 27$} & \multirow[t]{2}{*}{$\begin{array}{l}\text { Moving } \\
\text { through } \\
\text { herbology } \\
\text { halls }\end{array}$} & \multirow{2}{*}{$\begin{array}{l}\text { Get } \\
\text { through the } \\
\text { room with } \\
\text { tree } \\
\text { jumping } \\
\text { and } \\
\text { snapping } \\
\text { plants }\end{array}$} & $\begin{array}{l}\text { Moves around } \\
\text { platform (and } \\
\text { gets bitten by } \\
\text { plant) }\end{array}$ & Subject & Rules & $\begin{array}{l}\text { Doesn't realise } \\
\text { that the plant } \\
\text { can reach her }\end{array}$ & \\
\hline & & & $\begin{array}{l}\text { Climbs back } \\
\text { up (gets bitten } \\
\text { again until she } \\
\text { falls back off) }\end{array}$ & Subject & Rules & $\begin{array}{l}\text { Thinks there } \\
\text { might be a path } \\
\text { past (edging } \\
\text { around the tree), } \\
\text { when there } \\
\text { isn't. }\end{array}$ & $\begin{array}{l}\text { Gives up } \\
\text { seeking a safe } \\
\text { path and tries } \\
\text { another route }\end{array}$ \\
\hline
\end{tabular}

Table 1: A section of the transcript produced in Case Study 1. 